\title{
Revamped Thrust on Women's Participation for their Entitlements under NRHM: A Study of Pipili Block in Puri District of Odisha
}

\section{Bhabani Priyadarshini Mohanty* and Smita Nayak**}

\begin{abstract}
Regardless of several growth-orientated policies implemented by the government, the widening economic, regional and gender disparities are posing challenges for the health sector. The health status of Indians, especially women is still a cause for serious concern, especially that of the rural population. The National Rural Health Mission (NRHM) was launched by Government of India with a view to bring about dramatic improvement in the health system and health status of the people, especially those living in rural areas. The study aimed to understand the knowledge level of women beneficiaries on NRHM related services. The study further focused on understanding the extent of availability and accessibility, challenges faced and the benefits received by women. The research work was carried out in three Gram Panchayats of in Pipili block of Puri District in Odisha. Multi stage sampling method was adopted to select the sample group for the study. The study was conducted among 278 women beneficiaries of NRHM. The researcher used 120 item semi structured and validated interview schedule for collecting the data. The study results show that there is a need to strengthen the grass root level interventions in terms of strengthening the subcentres and involvement of Gram Panchayat in fulfilling the health mission objectives of the
\end{abstract}

\footnotetext{
*Research Scholar, PG Department of Political Science, Utkal University, Bhubaneswar, India **Head, Post Graduate Department of Political Science, Utkal University, Bhubaneswar, India E-mail: nayaksmita1992@gmail.com
} 
country. The Correlation between the knowledge scores and benefits scores was significant $(r=.705, P>.001)$. The study suggests having effective monitoring and evaluation mechanisms at all levels with clearly designed indicators and means of verification to ensure the success of the programme.

KEYWORDS: NRHM, Women Beneficiaries, Accredited Social Health Activist, Gram Panchayat, Anganwadi

\section{INTRODUCTION}

India has $16 \%$ of the world's population but only $2.4 \%$ of its landmass, resulting in great pressures for resources. It is a country where $70 \%$ of the population resides in a rural area and males significantly outnumber females, an imbalance that has increased over time. ${ }^{1}$ The typical female advantage in life expectancy is not seen in India and this suggests there are systematic problems in women's health care. Indian women have high mortality rates, particularly during childhood and in their reproductive years. India's maternal mortality rates in rural areas are among the world's highest. From a global perspective, India accounts for $19 \%$ of all live births and $27 \%$ of all maternal deaths. The health of Indian women is intrinsically linked to their status in society, especially for those living in a rural area. Research into women's status in society has found that the contributions Indian women make to families are often overlooked. Instead, they are often regarded as economic burdens and this view is common in rural areas of the northern belt. ${ }^{2}$ There is a strong preference for sons in India because they are expected to care for ageing parents. This son preference and high dowry costs for daughters' marriage results in the mistreatment of daughters. Indeed, Indian women have low levels of both education and formal labor-force participation. They typically have little autonomy, living first under the control of their fathers, then their husbands, and finally their sons: . These factors have a negative impact on the health status of Indian women. Poor health has repercussions not only for women, but also their families. Women in poor health are more likely to give birth to low weight infants. They are less likely to be able to provide food and adequate care for their children. Finally, a woman's health affects the household's economic wellbeing because a woman in poor health will be less productive in the labor force. ${ }^{3}$ In rural areas where women are less educated and economically deprived, their health condition is worse. In the context of health as defined by WHO - '...a state of 
complete physical, mental and social well-being and not merely the absence of disease or infirmity' ${ }^{4}$, one must ask how can this be achieved for Indian women. The main aim of NRHM is to provide accessible, affordable, accountable, effective and reliable primary health care facilities, especially to the poor and vulnerable sections of the population. The mission further seeks to build greater ownership of the programme in the community through involvement of Panchayati Raj Institutions (PRIs), NGOs and other stakeholders at national, state, district and sub-district levels. ${ }^{5}$ Given the wide scope of the Mission and multiplicity of activities and being in the 16th year of existence, an appraisal study of NRHM has been carried out by the researcher with an objective of evaluation and assessment of the availability, adequacy and utilization of health services in the rural areas, the role played by ASHAs, AYUSH in creating awareness of health, nutrition among the rural population and to identify the constraints and catalysts in the implementation of the NRHM programmes. Along with role of ASHA and mainstreaming of AYUSH the utilization aspects of health services necessitate studying other crucial factors like availability, planning and preparedness of health facilities and human resources, drugs availability, quality of $\mathrm{MCH}$ care and diagnostic-services, referral services, process of accreditation, effective decentralization, effective utilization of funds, etc. Simultaneous attention on programs impacting nutrition, capacity building, empowerment, etc. are equally important for effective utilization of the health services. All these interconnected aspects for promotion for utilization of healthcare system in rural areas have been brought under the purview of the present study. The present study focuses on the analytical exposition of paradigm shift from provisioning to entitlement approach furthered by NRHM in Pipili block of Puri District in Odisha to strengthen empowerment of rural women.

\section{REVIEW OF LITERATURE}

The researcher reviewed the studies conducted on functioning of within the last decade. A thorough examination of the available literature shows that NRHM has resulted in the betterment of funds related to health besides ameliorating the infrastructure associated with health delivery. It has improved health care delivery in many regions (Jacob, 2010) ${ }^{6}$. The studies show that most of the Accredited Social Health Activists (ASHA) has been able to fathom their part with respect to providing assistance to the expectant mothers by taking them to the medical institutions. They have also understood their duties pertaining to providing counseling to the communities in matters related to breastfeeding, ANC, PNC, 
immunization and the prevention of sexually transmitted diseases and also of reproductive tract infection.

It has been seen that monetary benefits give a significant push to ASHA and as a result, site based activities and delivery related activities are fast gaining the reputation of being an extremely pivotal domain to the same (Deoki, 2007) ${ }^{7}$. Studies also reveal that the OPD visits have increased at all three levels. It is also notable that there was no significant increase in service delivery in the initial two years of NRHM (Kumar et al., 2009) ${ }^{8}$. This was due to the initial phase of the implementation where the entire system was not in place and the awareness about the scheme did not reach adequately to the masses. The number of institutional deliveries has significantly increased after 2007 courtesy the initiatives taken by NRHM (Parveen et al., 2011) ${ }^{9}$. It has been found out that facilities provided by ASHA are more likely to be availed by literate women who have delivered in the recent past and who hail from a relatively elevated socio-economic background. It has also been seen that Hindu women, women who are young and those whose status is comparatively lesser have greater probability of availing health services provided by ASHA regarding Ante Natal Care and Post Natal Care than the others. It was seen that females hailing from castes which are not regarded to be elevated have a higher probability to utilize antenatal care services and post natal care services. It was also found that women from lower castes were more likely to avail antenatal and postnatal care (Manish et al., 2010) ${ }^{10}$. Some of the prominent attempts are providing benefits offered by Janani Suraksha Yojana in order to promote institutional deliveries, rooting for the establishment of services in the domain of obstetrics, building the capacities of nurses and nurse midwives for a period of 14-21 days in order for them to become capable birth attendants (Paul et al., 2011) ${ }^{11}$. Steps are being taken to ensure the participation of NGOs in matters related to health delivery systems. There is an attempt to improve the infrastructure related to the training requirements of ASHA. Around 300 NGOs have been roped to assist with the training of ASHA.

Jagdish Bhatia (1993) ${ }^{12}$ in his study titled 'Levels and causes of maternal mortality in southern India' discusses that majority of the researches centered on the mortality rates of pregnant women and also those women who have just delivered rely solely on facts and figures taken from hospitals. The data provided by hospitals does not give the accurate picture concerning 
maternal mortality as it fails to include the number of deaths that take place during deliveries which are non institutional. In a country like India, a substantial number of deliveries still take place at the residence of the concerned person and hence, it becomes all the more important to include such instances as well while giving an account of maternal mortality. According to Kranti Suresh Vora (2012) ${ }^{13}$, rural women in India contribute in a lopsided manner to the nation's staggering maternal mortality ratio. In response to this problem, the Indian government introduced a conditional cash transfer scheme, "Janani Suraksha Yojana (JSY)," in 2005 to ameliorate the reach of maternal health care among the women belonging to weaker sections. This study investigated the role of JSY/government assistance, and other health care sector and household factors in estimating the usage patterns with respect to maternal health facilities by the village women belonging to the economically backward sections of the society in the 2 states mentioned above. Health care sector factors included receipt of JSY payment, provision of a primary health center with 24 hour facilities, and connection to a health institution by a durable road. Household factors included maternal education, paternal education, age at first birth and parity. The use of the following four maternal health care services was examined: adequate antenatal care, institutional delivery, private facility delivery and Cesarean section. State findings were compared and contextualized by examining health polices/practices and health infrastructure within each state.

A study conducted by Rani et.al (2008) ${ }^{14}$ titled 'Differentials in the Quality of Antenatal Care in India' found out that the Northern states as well as the Southern ones have quality of antenatal care which is not as per the prescribed standards. However, South India fared relatively better than North India, especially with respect to women belonging to backward sections of the society. It was seen that North India had more pronounced differences in terms of the socio economic variables determining the quality of care compared to South India. However, the fact remains that both the regions showed considerable differences with respect to socio economic variables determining quality of care. A healthy relationship of paramount importance was seen with respect to the quality of the antenatal care and its usage in the rural regions as part of the multivariate analysis. A major reason behind the antenatal care services not being used optimally is the low quality of the same. It is essential to introduce more measures (policies, program based interventions etc.) in order to 
ameliorate the condition of maternal care in the country, especially, with respect to the people belonging to the poverty stricken sections of the society more so, in North India. It is important for the National Rural Health Mission, to stress more on ameliorating antenatal care in the country in order to elevate the condition of maternal health.

Sharma et.al (2012) ${ }^{15}$ has done a study on the impact of NRHM in its antenatal care mainly in urban and rural areas. The study was conducted at a Primary Health Center among 682 women, hailing from both urban and rural areas varying in age, different social background and religion. The study shows 46 that $58.5 \%$ of women, of both urban and rural areas had utilized ANC services in their first trimester itself. The interesting finding is that both educated and uneducated women had received the ANC services, and hence, education was not an influencing factor. In rural areas, the service of ASHA and other health workers had motivated, encouraged and convinced the women to utilize the service of NRHM. 86.5\% of urban women and $70.4 \%$ of rural women had their ANC visit more than three times. The study shows that the socioeconomic and religious factors are the only influential ones in the antenatal care services.

\section{STATEMENT OF RESEARCH PROBLEM}

The literatures show that women are one of the major beneficiaries of NRHM programmes in the country. NRHM focuses on providing health services to rural women in a manner which is affordable, accessible and effective. The Mission appears to be a step in the right direction as the rural women face many health challenges. The awareness level pertaining to NRHM and the accessibility of its services were also a major concern of this research. This research was mainly concerned about the state of knowledge, accessibility and availability, benefits and challenges of the programmes centered on rural women beneficiaries. It also aimed to study the socio demographic variables influencing the benefits of NRHM. Since NRHM started as a strategy to improve the health infrastructure of the country, this study has great significance to understand the grass root realities felt by the women beneficiaries. The study was undertaken keeping the perspective of community participation, entitlement and sense of ownership in mind and it was a micro analysis of the variables featured under NRHM. Since the Pipili Block in Puri District of Odisha being a suburban block has been recognized by the 
Government for having representative health indicators, the implementation of NRHM will have great significance over there.

\section{SIGNIFICANCE OF THE RESEARCH}

The major part of the benefit under NRHM is scheduled for women. A plethora of innovations are introduced under NHM by the Central Government and the State Governments. All these innovations are looking to provide quality healthcare to rural population, especially women at an affordable price and in an accessible manner. This study was an attempt to understand the perception, participation and ownership exhibited by women beneficiaries residing in the selected GPs of Pipili Block in Puri District of Odisha with respect to their knowledge about the programmes, availability and accessibility of the services, challenges faced in availing the services and the benefits received from NRHM. From the point of view of community participation for healthcare monitoring system, this research will focus more on how much the rural women are benefitted out of the interventions under NRHM and to see the reasons behind their not getting benefitted if that is the case. The results of the study will lead to the understanding of the interventions made under NRHM, besides developing strategies for effective intervention mechanisms if needed and understanding the issues faced by rural women in availing the services.

\section{OBJECTIVES OF THE STUDY}

The research makes an articulate attempt to focus on the following key objectives:

1. To assess the level of participation of women beneficiaries in community-based monitoring of NRHM pertaining to Pipili Block in Puri District of Odisha

2. To understand the extent of availability and accessibility of National Rural Health Mission services to women beneficiaries of the selected GPs of Pipili Block in Puri District of Odisha

3. To find out the challenges faced by women in managing community-based monitoring system and describe the benefits received by women beneficiaries of Pipili Block in Puri District

4. To study the relevance of socio demographic variables of Pipili Block in Puri District of Odisha in the context of accessing National Rural Health Mission services 


\section{OPERATIONALISATION OF THE CONCEPTS}

The operational definitions of the variables used in the study are mentioned below.

\section{Rural Women Beneficiaries:}

All women in the age group of 18-60 years from selected GPs of Pipili Block in Puri District of Odisha to receive benefits under NRHM.

\section{NRHM \& NHM:}

The Indian Government initiated the National Rural Health Mission in 2005 with the intention of bringing reforms to the landscape of the country's health care delivery system. The Mission has made an attempt to amalgamate health with the indicators of sound health such as sanitation, good quality drinking water, nutrition and hygiene. One of the vital objectives of the National Rural Health Mission is to make the Indian systems of medicine more universal so that they do not remain niche and limited (NRHM Mission Document). The Union Cabinet vide its decision dated 1st May 2013, has approved the launch of National Urban Health Mission (NUHM) as a Sub-mission of an overarching National Health Mission (NHM), with National Rural Health Mission (NRHM) being the other Sub-mission of National Health Mission. ${ }^{16}$

3. Knowledge and Participation:

Knowledge of NRHM services under this research is defined as knowing about the aim, objectives, facilities, grants available and special schemes under by women beneficiaries of Pipili Block.

\section{Accessibility:}

Accessibility of NRHM services in this study is defined as the extent of approachability to services of Accredited Social Health Activists (ASHA), Physicians and Specialists, Health care centers, mobile units and emergency services like ambulance.

\section{Availability:}

This variable in the study is defined as the availability of immunization services, primary health care, institutional deliveries, care for chronic illness, prevention of communicable illness, health education, home based care, nutritious food and grants from NRHM services.

6. Benefits from Services: Benefits from NRHM Services in this research are defined as the advantages which have been received by women after the implementation of NRHM such as free or subsidized medication, free or subsidized diagnostic services, free medical 
advice, free or subsidized surgical interventions, grants and schemes or the improvement of existing health care services.

\section{Challenges:}

Challenges faced by rural women beneficiaries in this study is defined as the issues and difficulties the women beneficiaries face in availing NRHM Services such as challenges faced in approaching ASHA, availability of ANM, condition of roads, awareness programmes on health issues, family and community support for availing treatments, quality of services at CHCs and PHCs and availability of medicines.

\section{STUDYING THE VARIABLES}

The researcher had made a systematic analysis of the following variables:

- Knowledge on NRHM services

- Availability and accessibility of NRHM services

- Benefits received from NRHM Services

- Challenges faced by women beneficiaries

- Socio Demographic variables namely:

- Age, Religion, Caste, Education, Source of Income, Size of the family etc

\section{PROFILE OF THE STUDY AREA}

To accomplish the objectives stated above, the research work was conducted in selected GPs of Pipili Block in Puri District of Odisha. Puri is the 21st district in terms of size and 9th in terms of population. Puri is the 9th urbanized district in state having 15.60 percent of its population live in urban areas as against 16.69 percent of state's population living in urban areas. Puri is 8 th densely populated district in the state. Puri has 22 nd rank in terms of sex ratio in the state. The key indicators of health status of the district are captured below:

- Geographical Area of Puri District: 3079 sq kms.

- Population as per 2011 census: 16,98,730

- Total No. of Blocks: 11

- Total No. of Urban Areas: 4

- Total No. of G.P.: 268

- No. of uninhabited villages: 124 
- Total No. of Villages: 1722

- No. of Tehsils: 11

- Total No. of Ayurvedic College: 1

- Total No. of Ayurvedic Dispensary: 7

- Total No. of Homoeopathic Dispensary: 9

IMPORTANT INDICATORS: (SOURCE: ANNUAL HEALTH SURVEY) ${ }^{16}$

- Infant Mortality Rate - 75

- Maternal Mortality Rate (central zone) - 218

- $\quad$ Crude Birth Rate - 17.5

- Neo-natal Mortality Rate -42

- Under Five Mortality Rate - 108

- Sex Ratio at Birth - 906

- Sex Ratio all ages - 966

\section{MAJOR ONGOING PROGRAMMES}

- Reproductive and Child Health (RMNCH+A)

- NRHM Initiatives \& Immunization

- Integrated Disease Surveillance Programmes (IDSP)

- Revised National Tuberculosis Control Programme (RNTCP)

- National Vector borne disease control programme (NVBDCP)

- National Blindness Control Programme (NPCB)

- National Tobacco Control Programme (NTCP)

- National Leprosy Eradication programme.(NLEP)

- District Mental Health Programme (DMHP)

- National programme for prevention and control of Cancer ,Diabetes, Cardiovascular diseases and Stroke (NPCDCS)

\section{MAJOR IMMUNIZATION CAMPAIGN \& LAUNCHING OF NEW VACCINES 2017-18}

- Introduction of JE (Japanese Encephalitis Vaccination Campaign) (27.11.17 - 31.12.17) Target: 460479, Achievement: 336404 (73\%) 
- Introduction of MR (Measles Rubella Immunization Campaign) (29.01.18 - 06.04.18) Target: 366507, Achievement: 362594 (99\%)

- Pulse Polio Vaccination Campaign (02.04.18 - 04.04.18) Target: 175882, Achievement: 176708 (100.47\%)

\section{SAMPLING DESIGN}

The study was focused on women who have been living in these three GPs coming under Pipili Block in Puri District for at least 2 years and who belong to the age group of 18-60 years. Another criteria set for the study was that the name of women participants was registered in the local ration card. The population of the study was the women beneficiaries of $3 \mathrm{Gram}$ Panchayats. This population is adopted from the total women beneficiaries of Pipili Block in Puri District of Odisha who form the universe of the study.

\begin{tabular}{|c|c|c|c|c|}
\hline $\begin{array}{l}\text { Rural Women } \\
\text { Beneficiary } \\
\text { Categories }\end{array}$ & $\begin{array}{l}\text { Name of the GP in } \\
\text { Pipili Block of Puri } \\
\text { District }\end{array}$ & $\begin{array}{l}\text { Census Data } \\
2011 \\
\text { (Women) }\end{array}$ & Quota & $\begin{array}{l}\text { Samples } \\
\text { taken for } \\
\text { the Study }\end{array}$ \\
\hline General & Dandamukundapur & 842 & 34 & 94 \\
\hline SC & Dandamukundapur & 32 & 3 & 15 \\
\hline General & Lakshminarayanpur & 281 & 28 & 36 \\
\hline SC & Lakshminarayanpur & 76 & 8 & 30 \\
\hline General & Birapurusottampur & 897 & 90 & 98 \\
\hline SC & Birapurusottampur & 15 & 2 & 5 \\
\hline
\end{tabular}

\section{Inclusion and Exclusion Criteria}

- Women who have been living in these village Panchayats for at least 2 years

- Women who belong to the age group of 18-60 years

- Women whose names are registered in the local ration card

\section{Exclusion Criteria}

- Women who have psychological and neurological disorders which prevent them to comprehend questions asked during the interview 


\section{Ethical Considerations}

The research adhered to the following ethical considerations:

- Obtained informed consent from participants besides keeping in mind the participants' honor, well-being and privacy

- Enlightened the participants about their right to cease participation in the research sans providing any justification

- Safeguarded participants from gratuitous physical or mental agony, hurt, threat, or deprivation

- The researcher shared the gathered data solely for academic intent and only with people professionally linked with the gathered information

- The researcher focused on keeping the identity of the participants and the information provided by them as classified

\section{Tools for Data Collection}

The researcher used a semi structured interview schedule for collecting the data. It was a 120 item tool developed by the researcher and validated by experts. The face validity of the tool was established with the help of the experts who have proven expertise in the field of research. Researcher conducted a pilot study using the tool developed and necessary changes were made in the scoring pattern after consulting the experts. The researcher also conducted focus group discussions with participants to have more clarity about the research area. The researcher conducted 3 focus group discussions in three village Panchayats. The Focus group discussion was focused on the general understanding of women in terms of the services provided under NRHM in their Gram Panchayats.

\section{Validation Procedures}

Face validity of the tool was established by giving the material to five experts and then making the necessary changes according to the suggestions provided by them. A pilot study was conducted by the researcher administering the tool in the field and certain modifications in terms of the scoring were made. It was found during the pilot study that 72 majority of the women beneficiaries either had a tribal background or belonged to a scheduled caste and hence, were unable to follow the four-point scale rating used by the researcher. The process 
was time consuming and unwillingness of the women to participate in the study added to the woes. The scaling was further changed to 2-point scale which was easy for the participants to comprehend.

\section{FIELD STUDY ANALYSIS}

The research was undertaken in the following phases:

1. Pilot visits were made to the villages in order to be familiar with the local conditions and also to build rapport with the people of the community. Initial focus group discussions were held with the Panchayat members, ASHA workers and group of women as per their availability. Purpose of the research was explained to the group and an initial consent was sought.

2. The second phase of the research work revolved around the pilot study conducted with 30 participants.

3. Data collection for the main study was done during the third phase of the field work. A quota of 215 participants was proposed for the study. The final data was collected from 278 participants. The unavailability of participants for the study was another major issue during data collection. Since majority of them are agricultural laborers, the participants were unavailable during the daytime

\section{Tools Employed for Analysis of Data}

The researcher coded and entered the data into SPSS software for analysis. Descriptive statistics was implemented in order to explain about the variables i.e. mean, standard deviation and frequency distribution. Pearson Correlation was used to find out about the association of variables used in the study. Chi square test of association was done to see 73 if knowledge about NRHM was associated with any of the socio demographic variables. MannWhitney Test was used to compare the study variables between people who had heard about NRHM and those who had not heard about the same. Mann-Whitney Test is a non-parametric equivalent of t-test. The Mann-Whitney Test was used because there were fewer participants in one category compared to the number of participants in the other category 


\section{MAJOR FINDINGS OF THE STUDY}

\section{Socio-Demographic Profile of the Study Area}

The study results show that the age group of most of the participants of the study was between $26-33$ years (42.8\%). All the 121 participants of the study follow Hinduism. SC population forms a major part in these village Panchayats. Majority of the participants (71.9\%) are above poverty line (BPL). $84.9 \%$ of the participants belong to nuclear families. Majority of the participants $(80.9 \%)$ got married only after they became of marriageable age. Illiteracy is not a major problem in the area as $63.3 \%$ of the participants are literate. $84.9 \%$ of participants are Agriculture Laborers and out of 278 participants, 252 do not have any land. Majority of the participants (93.5\%) live in pucca houses. Electricity is available to majority of the participants. When asked about the availability of toilets at their home, majority (98.2\%) answered in positive. Majority (87.8\%) of the participants use hand pumps provided by the Panchayat to avail drinking water. $\mathbf{7 7 . 3 \%}$ participants have access to grocery and vegetable shop near their house.

\section{Accessibility of NRHM services to Women Beneficiaries}

This part of the findings deals with the availability and accessibility of health systems and health personnel to the participants. The results of the study show that the response from the participants is mixed in terms of accessibility of Sub centre and Primary health centre. Sub centre is considered as the first meeting point for all the health-related needs of the community which is accessible to only $51.1 \%$ of participants. The Primary Health Centre (PHC) is the second layer in the three tier system and is accessible to $61.2 \%$ of participants. Majority of the people agreed to the availability of doctors at the Primary Health Centre (PHC) and the Community Health Centre (CHC). The results show that ASHA workers' visit to the households is frequent for majority (70.5\%) of participants. Majority (62.9\%) opined that the ANM is available in the sub centre. The study also reveals that $60.4 \%(168)$ of participants disagreed to the frequent visit of ANM to their villages.

\section{Challenges faced by women beneficiaries}

The study findings show that $55 \%$ of women face challenges in approaching ASHA. $56.5 \%$ (157) of women opined that ASHA is not available during emergencies. Majority of the participants (60.4\%) responded that ANM is not available in the sub centers. Lack of 
ambulance services is another major challenge shared by $76.6 \%$ (213) participants. Majority of the participants (68.7\%) said that there are no programs for them on health issues. 195 (70.1\%) participants were of the opinion that their family does not support them to go to hospital for treatment. When asked about the support of community for hospital deliveries, majority (64.7\%) responded in positive. $55 \%$ of (153) women opined that the Government hospitals do not provide good services. 181 participants (65.1\%) responded that sufficient beds are not provided in the PHC for patients. The findings of the study also show that there is a lack of sufficient 125 medicines in all the three tiers of health systems. Majority of the participants (66.9\%) disagreed about the Panchayats taking initiatives in improving health facilities. There are $66.9 \%$ participants who expressed interest in receiving NRHM benefits.

\section{Benefits Received by Women}

The study results show that only $37.4 \%$ (104) out 278 participants received the cash incentives under Janani Suraksha Yojana. It is found that $37.4 \%$ participants had their delivery at hospitals. There is no significant association between the age group and caste of people who avail the benefits of this scheme. Majority (60.8\%) of the participants said that they received assistance from ASHA. The intervention by ASHA for pregnant women was found to be significant. According to $38.5 \%$ of participants, there has been major improvement in the condition of sub centers after NRHM. According to 58.6\% (163) participants the health facilities have improved in the last five years. It was found that the women beneficiaries had difficulty in availing the benefits of the scheme. The study shows that the services of Anganwadi are effective in the sampled villages. Majority of them responded that their children receive nutritious food from Anganwadi Centres.

\section{ASSOCIATION OF STUDY VARIABLES AND ENTITLEMENTS UNDER NRHM}

The study found significant association between caste and electricity at home and knowledge about NRHM. There is no significant association between age, type of family, marital status and knowledge about NRHM. The mean score on 'Knowledge', between 'No' and 'Yes' group was found to be significantly different (Mann-Whitney $U=3899.0, P=.006$ ). In a similar way, the mean scores of 'Availability and Accessibility' between 'No' and 'Yes' group was also found significantly different (Mann-Whitney $\mathrm{U}=1696.0, \mathrm{P}=>.001$ ). A similar test was administered to assess the difference between 'Challenges' and 'Benefits' variables. The mean score on 
'Challenges', between 'No' and 'Yes' group was found significantly different (Mann-Whitney $\mathrm{U}=2032.0, \mathrm{P}=.001$ ) and the mean score on 'Benefits', between 'No' and 'Yes' group was also found significantly different (Mann-Whitney $U=1908.5, P=.001$ ). The correlation between the knowledge scores and challenges scores was found significant $(r=.246, \mathrm{P}>.001)$. The correlation between the knowledge scores and benefits scores was significant $(r=.705$, $\mathrm{P}>$.001). The correlation between the knowledge scores and availability and accessibility scores was significant $(r=.735, \mathrm{P}>.001)$.

\section{SUGGESTIONS AND RECOMMENDATIONS}

The study recommends initiation of programs for skill building of Accredited Social Health Activists (ASHA) since they play a vital role in National Rural Health Mission. Awareness programs at massive level are required to enable the community to understand each and every component of NRHM. The role of the health staff at Sub Centre, Primary Health Centre and Community Health Centre ought to be performed effectively to avoid delays in the provision of services to the people during emergencies. Monitoring and evaluation mechanisms need to be strengthened at all levels with clearly designed indicators and means of verification.

\section{IMPLICATIONS OF THE STUDY}

The results of the study could positively influence the policy makers to develop strategies in designing programme deliveries. It will further help the Panchayats to strengthen their capabilities and understand the role of local self-governing bodies at the village level in a better way. The research could help the NGOs working in the area to design intervention strategies required to strengthen the outlook of people towards Government programs. The study has its implication to social work since it promotes understanding of the grass root realities of any government programme. Social work methods like Social Group Work, Community Organization and Social Action can be effectively practiced in the intervention programme. Effective intervention strategies can be developed by using the Asset Based

Community Development, Locality Development and Social Action models of community organization. 


\section{LIMITATIONS OF THE STUDY}

Since the study was limited to three village Panchayats the results cannot be generalized. Rapport building at the community and hesitation of women participants to interact with the researcher in the initial stages was also another limitation of the study. Lacking more statistical analysis in the research is found as another limitation. Non participation of Panchayat Leaders was one of the major challenges for the researcher while collecting the data.

\section{SCOPE FOR FURTHER RESEARCH}

Further research can be undertaken by incorporating more regions of the state which may give a comprehensive understanding and generalized perspective to the topic. Studies can be incorporated by taking samples from both, backward and forward districts of the state to make comparative analysis of the situations. Action researches can be facilitated in this area where an in-depth pre test, intervention and post test could be conducted, which may have more acceptability and authenticity. A comparative analysis of states could be conducted to understand the level of community in to the programme. A mixed research methodology could be adopted to have both qualitative and quantitative inputs.

\section{CONCLUDING OBSERVATIONS}

The research findings show that the impact of NRHM is average in terms of its availability and accessibility among the rural women. There is a need to strengthen the grass root level interventions in terms of strengthening the sub centers and involvement of the Gram Panchayat in fulfilling the health mission objectives of the country. The NRHM services do reach the villages of the country but a holistic approach in terms of incorporating all the objectives of the programme and its implementation is required. There is a need to strengthen the capacity of ASHA, ANM and other health professionals. A major gap is found in the area of intervention of village Panchayats in terms of promoting health, hygiene and safe drinking water. The study found that NRHM has succeeded in reaching to the rural communities. Participants acknowledged to have faced challenges in a few areas in terms of approachability and availability of Accredited Social Health Activist (ASHA) and Auxiliary Nurse and Mid wife (ANM) at the village and sub centre level. Quality of facilities provided by Government hospitals was another challenge for the participants. Lack of initiatives of the 
Panchayat in the improvement of health of the village was found as another challenge for the people. Provision of nutritious food to pregnant women and children was another area of challenge faced by the participants. Majority of the participants have not showed any interest in availing NRHM services. When asked further, they clarified that the quality and delay in availing services force them to go to private hospitals for treatment. They also discussed that the PHC has no sufficient beds for the patients. The study results further show that the mean scores of 'Knowledge', 'Availability and Accessibility', 'Challenges' and 'Benefits' are significantly different. A significant correlation was observed between the total scores of knowledge, challenges, benefits and availability and accessibility.

\section{ENDNOTES}

1. Chatterjee M. Indian women: their health and economic productivity, World Bank Discussion paper 109. Washington, DC: World Bank, 1990.

2. Desai S. Gender inequalities and demographic behavior, India. New York: The Population Council, 1994

3. Horowitz B, Madhu K. Family life - the unequal deal. In: K Madhu, R Vanita (Eds). In search of answers: Indian women's voices from Manushi, London . India Registrar General: India Registrar General, 1992.

4. World Bank. Improving women's Health in India. Washington, DC: World Bank, 1996.

5. Evaluation Study of National Rural Health Mission (NRHM) in 7 States web source: https://dmeo.gov.in/2019/Evaluation/Report

6. Jacob, K. S. (2010, December 29). NRHM: addressing the challenges. The Hindu. Retrieved from http://www.thehindu.com/opinion/lead/nrhm-addressing-the-challenges/article 1016403.ece

7. Deoki, N. (2007). A rapid appraisal of functioning of ASHA under NRHM in Cuttack, Orissa. Retrieved from website: http://nih fw.org/pdf/ RAHI-I Reports/Cuttack/CUTTACK.pdf

8. Kumar, K., Sankhe, L., Singh, P. K., Tomar, J., \& Baijal, S. (2009). An analysis of utilization of health services under national rural health mission: A case study of selected district of Uttar Pradesh, India. Retrieved from Available at SSRN: http://ssrn.com

9. Parveen, S., \& Abhijit, D. (2011). Understanding Women's Perception of Quality of Care: Implications. New Delhi : Centre for Health and Social Justice. 
10. Manish, K. S., Singh, J. V., Reema, K., \& Khanna, A. (2010). Factors influencing utilization of ASHA services under NRHM in relation to maternal health in rural Lucknow. Indian Journal of Community Medicine, 35(3), 414-419. Retrieved from http://www.ncbi. nlm.nih.gov/pmc

11. Paul, V. et.al. (2011). India: Towards universal health coverage 2. The Lancet, 377(9762), 332-33. Retrieved from http://search.proquest.com/docview

12. Bhatia, J. C. (1993). Levels and causes of maternal mortality in southern India. Studies in family planning, 310-318.

13. Vora, K. S. (2012). Implementation of Janani Suraksha Yojana and other maternal health policies in two Indian states: Predictors of maternal health service utilization among poor rural women

14. Rani, M., Bonu, S., \& Harvey, S. (2008). Differentials in the quality of antenatal care in India. International journal for quality in health care, 20(1), 62-71.

15. Sharma, V., Mohan, U., Das, V., \& Awasthi, S. (2012). Utilization pattern of antenatal care in Lucknow under National Rural Health Mission. Indian Journal of Community Health, 24(1)

16. NRHM Mission Document https://nhm.gov.in/WriteReadData/l892s/nrhm-frameworklatest.pdf

17. Annual Health Survey, Puri 2019, https://www.censusindia.gov.in/ 